\title{
Argentine adaptation of the Quality of Life Indicators guide for organizations that support people with autistic spectrum disorders
}

\author{
José L. Cuesta Gómez, M.D ${ }^{a, b}$ and Luisa A. Manzone, M.D. ${ }^{b, c, d, e}$
}

\begin{abstract}
This article describes the adaptation process of the Quality of Life Indicators guide for organizations that support people with autistic spectrum disorders which has taken place in Argentina (Cuesta, J. L., 2009) using the Delphi method, and with the participation of a group of autism-related experts from different fields and domesticinstitutions. The result is an instrument based on a quality-of-life model which is adjusted to the Argentine setting, helps planning and assessing centers and programs for people with autistic spectrum disorders, and responds to the increasing number of specific services which cover the needs of this population.

Key words: autistic spectrum disorder, quality of life, organization and management.
\end{abstract}

http: / / dx.doi.org/10.5546/ aap.2018.eng.e257

To cite: Cuesta Gómez JL, Manzone LA. Argentine adaptation of the Quality of Life Indicators guide for organizations that support people with autistic spectrum disorders. Arch Argent Pediatr 2018;116(2):e257-e266

a. School of Education, Universidad de Burgos.

b. Asociación Española de Profesionales del Autismo.

c. Fundación Trastornos del Espectro Autista, TEA.

d. Centro Argentino Integral de Tratamiento Individualizado, CAITI.

e. Asociación Argentina de Profesionales del EspectroAutista.

E-mail address:

Luisa A. Manzone, M.D.: caitisrltea@gmail.com

Funding:

None.

Conflict of interest: None.

Received: 6-7-2017

Accepted: 9-12-2017 often reflected in their inability to express their needs, wishes, level of satisfaction, physical or emotional conditions, in summary, to share information about themselves, basic issues which might allow an assessment of their quality of life..$^{2-12}$ It is on these difficulties that lays the need for instruments to guarantee that these organizations, as well as the interventions they offer, promote and assure the highest quality of life.

In the face of this situation, the research sustained that, while not leaving aside the use of scales or instruments to evaluate the subjective dimension, i.e. the person's own perception, it was specially important to emphasize the objective dimension as a way to assess and promote quality of life. Such issues, along with the difficulty in determining quality of life from a subjective perspective in people with ASD, make the validation of indicators which tend to promote certain conditions in the ASD person's environment particularly necessary. ${ }^{13-15}$

The intervention setting or environment itself should foster people with ASD's personal development and maximum participation throughout their lives, as is set forth by one of the main referents for disabilities, the International Classification of Functioning, Disability and Health. ${ }^{13}$

This work was the result of the need to have a tool which, adjusted to the Argentine setting, helped plan and assess how much institutions and programs were improving people with ASD's quality of life. Besides, this need arises from the results obtained in different studies which were carried out in Argentina and 
showed an increase in autism prevalence, in line with other international studies findings: 4.5 cases per 1000 births, ${ }^{16} 4.8$ per $1000^{17}$ and 14.6 per $1000 .{ }^{18}$

After a revision of the quality-of-life assessment instruments already in use, it was proved that most of them had not been designed for people with ASD, ${ }^{19-22}$ and only one specific instrument was found: the Quality of Life Indicators Guide for organizations that support people with autistic spectrum disorders. ${ }^{23}$ Using the Delphi method, ${ }^{23}$ this tool was designed and validated in Spain, based on the contributions of the most important ASD research referents ${ }^{24-26}$ and the best practice guidelines, ${ }^{11,27}$ and with the consensus of a group of 12 experts in autism, who belonged to different support services of various representative domestic organizations. Aiming to ensure maximum representativity, these experts had different professional profiles and backgrounds, and a minimum experience of five years' work with people with ASD of different ages and function levels.

The Quality of Life Indicators Guide provides an assessment instrument to work with from an objective perspective, which takes into account contextual factors related to organizations and services integrating ASD individuals, and which may significantly affect, directly or indirectly, their quality of life.

The instrument includes 67 indicators which are pooled in six fields: 1- Quality regarding the person, 2- Identification of their needs, creation and compliance with personal development plans, 3- Health care providers' training, 4- Structure and organization, 5- Personal, material and spatial resources, and 6- Relationship with the community/social outreach.

Each indicator features four evidences, four tests which help observing and making the indicator quantifiable, and certifying its compliance or non-compliance, with one single, objective assessment criterion for all evaluators.

The guide design makes it suitable to be implemented in different centers, support services and cultural contexts, since it focuses on evaluating aspects considered common, regardless of people with ASD's age or the type of service they receive. Besides, the assessment is presented in a flexible fashion and the use of an indicator is not required if the evaluating group judges it irrelevant.

The general purpose of the research dealt with in this article is the adaptation which has taken place in Argentina of the Quality of Life
Indicators Guide for organizations that support people with autistic spectrum disorders.

\section{METHOD}

\section{Selection of a research method}

The Delphi method, ${ }^{28,29}$ a consensus technique within a qualitative methodology, of the kind of in-depth group interview, was chosen to achieve the purpose of the study.

This tool was used in order to achieve consensus through the participation of a group of experts specialized in different aspects of a same field, so as to ensure a deep analysis from different perspectives and focus the attention based on different proposals..$^{30-32}$

In comparison to the physical meeting of groups where experts are invited to personally make their contributions and interchange opinions, anonymity, controlled feedback, independence, group representativity and data and researchers triangulation can be mentioned as strengths of using the e-mail. $28,29,33$

\section{Creation of the group of experts}

In this work, ${ }^{28}$ the Investigator assumed the role of a participating observer, thus integrating himself to the group of participants, and made contributions and proposals in addition to the consensus process of the whole group. ${ }^{28}$

The experts panel mission was to review the indicators guide in different phases, aiming to adapt the terminology, ensure the representativity of indicators and evidences, guarantee the objectivity of the evidences, and contribute any suggestion or proposal they judged necessary in order to improve it.

The group of experts was selected by the project coordinators and authors of this article, in accordance with the following criteria:

- Having worked in the field of ASD, with more than five years of experience and a solid reputation.

- Representing various disciplines related to ASD, and being able to contribute complementary perspectives.

- Representing different geographic areas.

Based on these criteria, it was decided that the group of experts be formed by ten professionals from universities, therapeutic education centers, centers of research and treatment of people with ASD, special education schools, and from the following locations: Autonomous City of Buenos Aires (CABA), West region of Province of Buenos 
Aires, North region of Province of Buenos Aires, Río Negro and Mendoza.

The experts were representative of complementary disciplines, all of them related to autism: Psychology, Phonoaudiology, Psichiatry and Education. Experts with well-known experience in the different evolution stages and diagnostic fields, direct intervention, family support, health and research were included.

\section{Instrument of reference}

As it was described above, the instrument of reference for the research features 67 indicators which are assessment measures useful to improve results. Their measure is significant and interpretable, and data can be easily collected. ${ }^{23}$

\section{Procedure}

In 2015, TEA Foundation (Buenos Aires) initiated the adaptation process with an exploratory phase during which, after the experts group formation, the $1^{\text {st }}$ version of the indicators guide was prepared, which allowed the initiation of the methodological sequence of three rounds or e-mail submissions ${ }^{30}$ through which a qualitative revision was made and the linguistic adaptations agreed upon (see Annex 1).

The 10 experts contacted initially participated actively throughout the whole process.

Upon reception of each of the submissions, the proposals were analyzed and those proposals with higher consensus were incorporated. Each submission started with a personalized answer to each expert explaining how their contributions had been considered, and including general information for the whole group regarding the contributions which had obtained the highest consensus.

\section{First submission}

The purpose of this round was to review and perform the qualitative adjustments the experts judged important based on the $1^{\text {st }}$ version of the indicators guide and its application methodology. The whole group agreed on the definition and model of quality of life, which justified the guide structure in the representativity of fields, indicators and evidences, and on the tool application methodology.

\section{Second submission}

The function of the panel of experts was to revise the terminology of the indicators guide content.
The most significant contributions helped adjusting or replacing some expressions which made it difficult to properly understand indicators and evidences. In addition, the denomination of terms referring to professional profiles mentioned in the guide was adjusted, and some concepts regarding the intervention with people with ASD were either replaced or clarified.

\section{Third submission}

All the reports obtained so far were summarized in this last stage, and an iterative consultation with the experts was made about the final guide version and its application methodology. At the same time, experts were consulted about the convenience of adapting some of the concepts submitted by the group, which, though lacking a high level of consensus, had been regarded by the coordinators as important enough to be reconsidered.

\section{VALIDATION PROCESS RESULTS}

The resulting Quality of Life Indicators Guide (see Annex 2) features 67 indicators, since neither the number was modified regarding the original version nor the fields in which they are grouped.

This guide is regarded as responsive to the organizations' support and conditions (planning and assessment of programs and services for people with ASD) necessary to improve the individual's quality of life.

Each indicator features four evidences assuring its realization and objectivity, regardless of the context or the evaluator (see Table 1). Some term adaptations from the Spanish version were made.

One of the results of this work is the Application Manual, which complements the Quality of Life Indicators Guide, and enforces its implementation, subject to consensus, by a consultant team which strictly guarantees not only that the objective outcome variables be taken into account, but also the most relevant subjective outcome measures which may affect the individual's participation settings. ${ }^{23}$

Once in the organization, the evaluating team, formed by an external evaluator who is in charge of the Service, a relative and, whenever possible, a person with ASD, will verify each of the indicators through the evidences.

The guide includes a software (OTEA) which automatically processes the input received and reports the global score by means of a graph which helps interpreting the organization status 
regarding each indicator. ${ }^{23}$

The process ends with the creation and submission of a final report (in parts) which includes general observations, indications about which aspects should be taken into account to improve the quality level, improvement guidelines, and a revision date, if necessary.

\section{DISCUSSION}

This work describes the adaptation and validation process of the Quality of Life Indicators Guide for organizations that support people with autistic spectrum disorders which took place in Argentina.

Not knowing exactly which is the purpose of the assessment to be performed, and therefore, not using the most suitable systems is a common mistake whenever a research on quality of life is carried out. ${ }^{34}$ In this particular research, when trying to assess the programs and services, and their adequacy for the persons who receive them, recurring to objective indicators is the correct thing to do.

The newest quality-of-life assessment models are based on a multidimensional vision which embraces all the areas, aspects and fields of a person's life, and features an objective perspective regarding contextual measurable conditions, which themselves help the person live a better life. ${ }^{1,3,8,15}$

\section{CONCLUSIONS}

The group of experts participating in the validation of the Quality of Life Indicators Guide in Argentina has regarded it as a valid instrument within its context to assess the impact of the services on the lives of people with ASD who receive them.

This tool is presented as a necessary resource for the multiple institutions which offer services for people with ASD in Argentina, as a reference for those who would like to address the challenge of implementing models based on quality of life, and as an incentive for all those who dream of and dare approach new ways of improving the quality of the support received by people with ASD.

The stage to complement the guide adaptation process in Argentina would be its dissemination through and implementation by different organizations in order to establish its reliability and consistency. At present, this project is under development.

\section{REFERENCES}

1. Reinders HS, Schalock RL. How organizations can enhance the quality of life of their clients and assess their results: the concept of QOL enhancement. Am J Intellect Dev Disabil 2014;119(4):291-302.

2. Billestedt E, Gillberg IC, Gillberg C. Aspects of quality of life in adults diagnosed with autism in childhood. Autism 2011;15(1):7-20.

3. Cuesta Gómez JL, Anuncibay R, González Bernal J, et al. A guide to indicators for the evaluation of specialist autism centres, based on the quality-of-life model. Int J Dev Disabil 2017:1-9. [Accessed on: September 20th, 2017]. Available at: http:/ / dx.doi.org/10.1080/20473869.2017.1361672.

4. Maxey D, Kezar A. Revealing Opportunities and Obstacles for Changing Non-Tenure-Track Faculty Practices: An Examination of Stakeholders' Awareness of Institutional Contradictions. J High Educ 2015;86(4):564-94.

5. Autism Speak. Educating for Excellence: Training Paraprofessionals in ASD Best Practices. 2013. [Accessed on: September 20th, 2017]. Available at: https:/ / www. autismspeaks.org/sites / default / files/the_autism_ project_final_report.pdf.

6. Witwer AN, Lecavalier L. Examining the validity of autism spectrum disorder subtypes. J Autism Dev Disord 2008;38(9):1611-24.

7. Povey C, Mills R, Gómez de la Cuesta G. Autism and ageing. Issues for the future. Midlife and Beyond 2011; 230-232.

8. Sheldick R, Neger E, Shipman D, et al. Quality of life of adolescents with autism spectrum disorders: concordance among adolescents self-reports, parents reports, and parents proxy reports. Qual Life Res 2012;21(1):53-7.

9. Shipman D, Shelrick R, Perrin E. Quality of life in adolescents with autism spectrum disorders: Reliability and validity of self-reports. J Dev Behav Pediatr 2011;32(2):85-9.

10. Stuart- Hamilton S, Griffith G, Totsika V, et al. The circumstances and support needs of older people with autism. 2009. [Accessed on: September 20th, 2017].

TABLE 1. Example: Indicator 9 evidences

Indicator 9: The person with ASD and his/her guardian participate in the planning, execution and assessment of their individual development plan.

- Evidences:

- There are participation and expression channels of people with ASD and/or their representatives in relation to the individual development plan.

- The persons involved received support in order to select options and make decisions.

- Personal aspirations or expectations, preferences and interests are analyzed and taken into account.

- Activities are adapted and structured in order that they guarantee their realization in the most autonomous possible way. 
Available at: http:/ / gov.wales/docs/dhss/report/1006 22olderpeoplewithautismreporten.pdf.

11. Güemes I, Martín Arribas MC, Canal Bedia R, et al. Evaluación de la eficacia de las intervenciones psicoeducativas en los trastornos del espectro autista. Madrid: Ministerio de Ciencia e Innovación-Instituto de Salud Carlos III; 2009.

12. Palomo Seldas R. Autismo: teorías explicativas actuales. Madrid: Alianza; 2017.

13. Barthélémy C, Fuentes J, Howlin P, et al. Persons with Autism SpectrumDisorders. Identification, Understanding, Intervention. Bruselas: Autism Europe; 2008.

14. Plimley LA. A review of quality of life issues and people with autism spectrum disorders. Br J Learn Disabil 2007; 35(4):205-13.

15. Cuesta-GómezJL, Vidriales-Fernández R, Carvajal-Molina F. Calidad de vida en niños y adolescentes con trastorno del espectro autista sin discapacidad intelectual. Rev Neurol 2016;62(Supl 1):S33-9.

16. García Coto MA. Autismo Infantil. Un estudio epidemiológico. [Dissertation]. CONICET, 77, 1985.

17. Manzone L. Adaptación y validación del M-CHAT para población urbana argentina. Investigacióne Innovación en Autismo. En: Asociación Española de Profesionales del Autismo. Investigación e innovación en autismo: AETAPI, premios "Ángel Rivière". 5.ta ed. Puerto Real: Asociación Española de Profesionales del Autismo; 2011:67-158.

18. ColantonioLlambías M, Salamanco G, Alfieri I, et al. Detección Precoz de Trastornos del Espectro Autista en niños de 18 a 30 meses en la consulta ambulatoria de un hospital público de C.A.B.A. $2^{\circ}$ Congreso Argentino de Discapacidad en Pediatría. September 27-29, 2012. Buenos Aires, Argentina; 2012.Págs.51-2.

19. Brown I, FriefeldS, SchillerC. Quality of life for persons with developmental disabilities: An annotated bibliography. The Centre for Health Promotion, University of Toronto, 2008.

20. Gómez-Vela M, Verdugo MA. Cuestionario de evaluación de la Calidad de Vida de alumnos adolescentes (CCVA). Madrid: CEPE. 2009.

21. Verdugo MA, Gómez L, Arias B, et al. Escala San Martín: evaluación de la calidad de vida de personas con discapacidades significativas. Santander: Fundación Obra San Martín; 2014.

22. Council on Quality and Leadership. Cross-walk between the CMS HCBS Quality framework and CQL's "Quality Measures" 2005. [Accessed on: September 20th, 2017]. Available at: http://www.nasuad.org/sites/nasuad/ files/hcbs / files / 72/3580/Crosswalk05.pdf.

23. Cuesta Gómez JL. Trastornos del espectro autista y calidad de vida: Guía de indicadores para evaluar organizaciones y servicios. Madrid: La Muralla; 2009.

24. Frith U. Autismo. Madrid: Alianza; 1999.

25. Tamarit J. Autismo: modelos educativos para una vida de calidad. Rev Neurol 2005;40(Supl 1):181-6.

26. MartínezMartínMA, Cuesta GómezJL. Todo sobreelautismo: Los trastornos del espectro autista. Guía completa basada en la ciencia y en la experiencia. Tarragona: Altaria; 2012.

27. Fuentes-Biggi J, Ferrari-Arroyo MJ, Boada-Muñoz L, et al. Guía de buena práctica para el tratamiento de los trastornos del espectro autista. Rev Neurol 2006;43:(7):425-38.

28. Ruiz Olabuénaga JI. Técnicas de triangulación y control de calidad en la investigación socioeducativa. Bilbao: Mensajero; 2003.

29. Cuesta Gómez JL. Aplicación de la técnica Delphi en el proceso de validación de un instrumento para la evaluación de la calidad de vida en centros para personas con Trastornos del Espectro Autista. Qurrículum 2013;26:13560.

30. González Rey FL. Investigación cualitativa y subjetividad. Los procesos de construcción de la información. México: McGraw Hill; 2007.

31. Tójar Hurtado JC. Investigación cualitativa. Comprender y actuar. Madrid: La Muralla; 2006.

32. De la Herrán A. Investigar en educación: fundamentos, aplicación y nuevas perspectivas. Madrid: Dilex; 2005.

33. Landeta Rodríguez J. El método Delphi: una técnica de previsión de futuro. Barcelona: Ariel; 1999.

34. Schalock RL, Gardner JF, Bradley VJ. Quality of life for people with intellectual and other developmental disabilities. Washington: American Association on Intellectual and Developmental Disabilities; 2007. 


\section{ANNEX 1}

Summary of the application of the Delphi method in the adaptation of the Quality of Life Indicators Guide for organizations that support people with autistic spectrum disorders in Argentina (Cuesta, 2009)

\section{PRELIMINARY STAGE}

- Setting of the group of experts selection criteria

- Definition of functions

- Experts selection

- Information and request to participate in the group of experts

- Indicators guide preparation by the coordinators

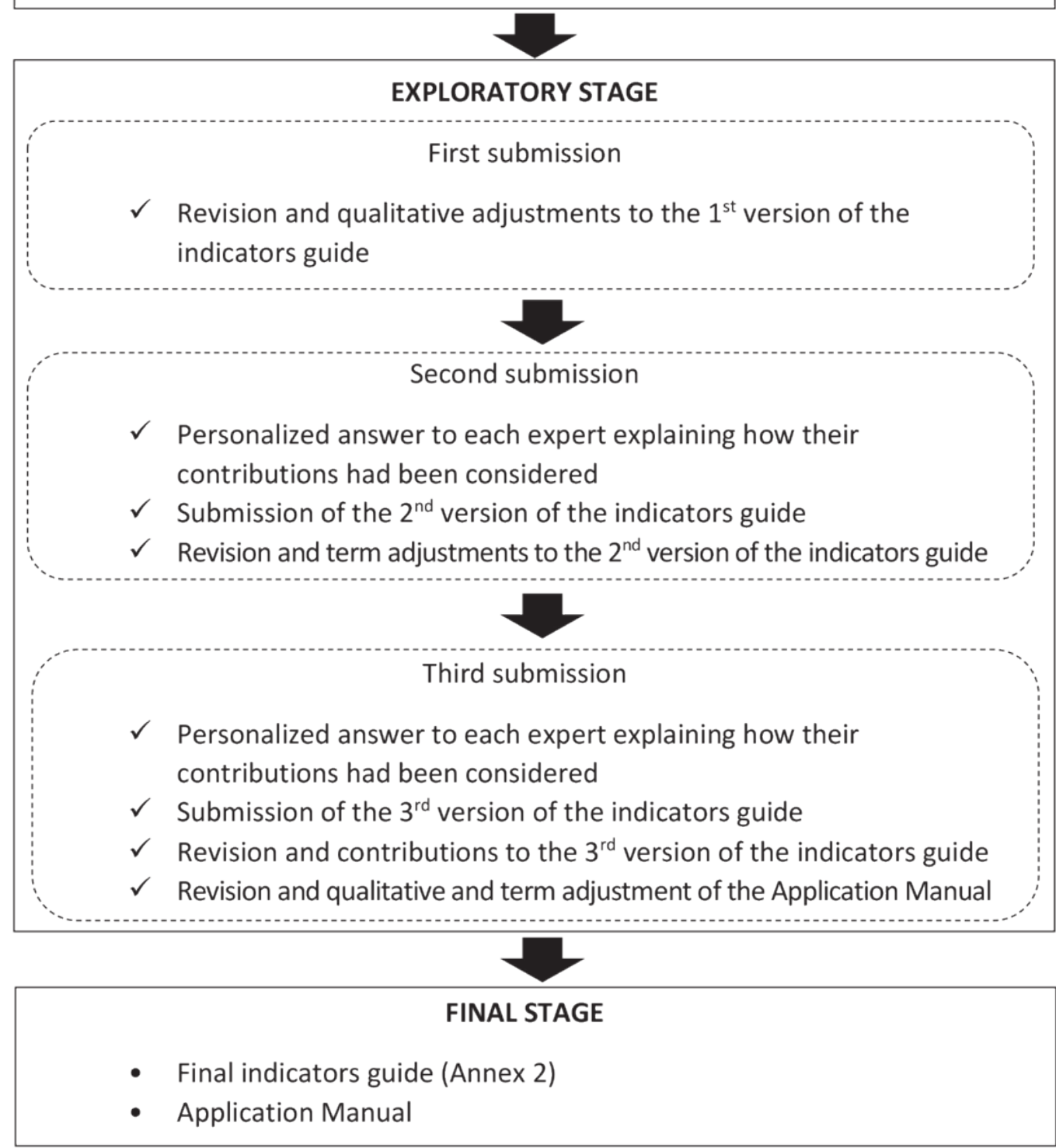


ANNEX 2

INDICATORS GUIDE

1. QUALITY REGARDING THE PERSON

1.1. Quality from the person with ASD's perspective

Physical well-being

Indicator 1: There are health care customized and updated programs available.

Indicator 2: The correct administration and follow-up of drug therapies is ensured.

Indicator 3: Individualized intervention within self-care and autonomy fields is taken into account.

Indicator 4: Actions are developed in relation to safety and hygiene in the different fields.

Indicator 5: Preventive, customized actions are considered in order to maintain a good health.

Emotional well-being

Indicator 6: The environment promotes a positive emotional status in people with ASD.

Indicator 7: Maximum emotional stability is promoted in the life of people with ASD.

Indicator 8: Customized positive behavioral intervention programs are developed.

Indicator 9: The person with ASD and his/her guardian participate in the planning, execution and assessment of their individual development plan.

Indicator 10: Customized personal support is available for people with ASD.

Material well-being

Indicator 11: There is respect for intimacy.

Indicator 12: Belongings are promoted and respected.

Interpersonal relationships

Indicator 13: Significant social relationships are promoted.

Personal development

Indicator 14: Individual capabilities and interests are promoted.

Indicator 15: Continuous personal progression and development are promoted. Rights

Indicator 16: Respect for the person's identity and dignity is guaranteed.

Indicator 17: Physical integrity is guaranteed.

Self-determination

Indicator 18: Diverse and adapted training is received previous to the generation of self-determination behaviors.

Indicator 19: Individuals participate in the planning and control their own life.

Social inclusion

Indicator 20: Social inclusion of people with ASD is promoted.

\subsection{Quality from the families' perspective}

Indicator 21: The actions implemented with the individuals with ASD take into account their families' expectations.

Indicator 22: Involvement of the families in the organization is facilitated.

Indicator 23: Families' satisfaction improvement is encouraged.

\subsection{Quality from the health care providers' perspective}

Indicator 24: Professionals' proposals and initiatives are acknowledged, assessed and taken into account.

Indicator 25: Health care providers' responsibilities are consistent with their functions.

Indicator 26: Participation and team work are promoted.

Indicator 27: Health care providers' satisfaction improvement is encouraged.

Indicator 28: Health care providers are involved in the organization. 


\section{IDENTIFICATION OF THE NEEDS AND PREFERENCES/ELABORATION AND FOLLOW-UP OF PERSONAL DEVELOPMENT PLANS}

\subsection{Programming}

Indicator 29: The needs, aspirations and expectations of person's with ASD regarding the different intervention fields are assessed.

Indicator 30: Intervention plans which are adapted to each individual's specific needs are elaborated throughout his/her life.

Indicator 31: The structure of the organization's general programming is adjusted to the characteristics of people with ASD.

Indicator 32: Personal development plans elaboration process is adjusted to the characteristics of people with ASD.

\subsection{Support planning}

Indicator 33: There is a planning and utilization process of the different supports which satisfies each individual's characteristics.

Indicator 34: Methodological criteria are adapted to the needs and capabilities of the person withASD. Indicator 35: Personal development plans are adapted to each individual.

\subsection{Follow-up and assessment plan}

Indicator 36: Each personal development plan is subject to continuous follow-up and assessment.

\section{HEALTH CARE PROVIDERS' TRAINING}

\subsection{Expertise on autism}

Indicator 37: Initial training for new health care providers is ensured.

Indicator 38: Training includes technical and organizational aspects, and the organization's values.

Indicator 39: Each health care provider receives specific training for his/her function.

Indicator 40: Continuous training, updating and professional development are promoted.

Indicator 41: The institution has its own resources to promote training, updating and professional development.

3.2. Knowledge of and adaptation to the person with ASD: person-centered planning (PCP)

Indicator 42: Each health care provider acts in accordance with the PCP principles.

Indicator 43: There is individualized information of each person with ASD.

Indicator 44: Each person with ASD is deeply and comprehensively known.

Indicator 45: The intervention is adjusted to each personal development plan (characteristics, needs, aspirations and expectations, personal preferences, etc.).

Specific and/or specialized support needs of each person are taken into account.

\subsection{Attitudes and values}

Indicator 46: The practice and professional attitudes are consistent with the organization's mission and values.

\subsection{Participation in autistic spectrum disorder research}

Indicator 47: The organization encourages the extension of knowledge through active participation in different research studies on ASD.

\section{STRUCTURE AND ORGANIZATION}

\subsection{Groups of mates}

Indicator 48: Groups of mates formation is adjusted to the characteristics of people with ASD.

Indicator 49: Health care providers are a clear reference for people with ASD. 


\subsection{Activity organization}

Indicator 50: Tasks and activities are organized.

Indicator 51: Responsibilities are assigned to people with ASD, who are actively involved in the organization.

Indicator 52: The professional team provides support and technical follow-up.

\subsection{Schedule}

Indicator 53: People with ASD's work timetables and rhythm are adjusted to their needs.

Indicator 54: The professionals' timetables and time distribution should adjust to people with ASD's needs.

\subsection{Communication/coordination}

Indicator 55: Communication is encouraged among all the persons involved in the organization.

Indicator 56: Times and spaces for coordination are planned and promoted.

Indicator 57: There is coordination with other programs and services related to people with ASD.

Indicator 58: Communication is facilitated to people with ASD.

\subsection{Systematic assessment of the service and/or the organization}

Indicator 59: An internal assessment of the organization is performed.

Indicator 60: An external assessment is considered for organization improvement.

\subsection{Leadership}

Indicator 61: The organization's management promotes continuous improvement.

\section{RESOURCES AND SERVICES}

Indicator 62: Human resources are utilized.

Indicator 63: Professionals' work is appropriately organized.

Schedules, activities and groups assigned to each health care provider throughout the working day are clearly structured.

Indicator 64: Material resources are utilized. Resources are available to all health care providers. Indicator 65: Physical environment favors people with ASD's participation, accessibility and autonomy.

\section{RELATIONSHIP WITH THE COMMUNITY/SOCIAL OUTREACH}

Indicator 66: There are cooperation agreements with other entities, regardless of their being involved (or not) in disability issues.

Indicator 67: The organization assumes a social responsibility commitment.

There is an external communication plan designed to release and offer information about autism: informative booklets, websites, publications, videos, presence in the social media. 